\title{
An experimental study on changes in sound absorption capability of spruce (Picea sitchensis), Douglas fir (Pseudotsuga menziesii), and larch (Larix kaempferi) after microwave treatment
}

\author{
Eun-Suk Jang and Chun-Won Kang ${ }^{*}$ (1)
}

\begin{abstract}
This study investigated changes in the sound absorption coefficients of three anatomical sections of cubed spruce (Picea sitchensis), Douglas fir (Pseudotsuga menziesii), and larch (Larix kaempferi) after microwave treatment. Microwave treatment at $1000 \mathrm{~W}$ and $2.4 \mathrm{GHz}$ for 20 min increased the sound absorption coefficients (at 2000-5000 Hz) of spruce by $6.9 \%$ in the transverse section, $20.0 \%$ in the radial section, and $31.7 \%$ in the tangential section. The sound absorption coefficients of Douglas fir increased by $28.9 \%$ in the transverse section, $19.1 \%$ in the radial section, and $50.0 \%$ in the tangential section. Larch coefficients increased by $16.7 \%$ in the transverse section, $37.2 \%$ in the radial section, and $38.8 \%$ in the tangential section. The sound absorption coefficients of the softwoods differed according to species and anatomical plane after microwave treatment. It was concluded that changes in the measured sound absorption coefficient indicate alteration in the pore structure of wood, which can affect in turn wood permeability and impregnation. These data will be helpful for predicting the permeability and impregnation of wood after microwave treatment.
\end{abstract}

Keywords: Sound absorption coefficient, Microwave treatment, Spruce, Douglas fir, Larch

\section{Introduction}

Permeability is an important physical property of wood that affects its drying properties, impregnation, and sound absorption [1-4], determining many of its applications as a porous material. Modifications for improving the gas permeability of wood have been studied since the 1930s, and remain a popular research topic [5]. For example, $\mathrm{Xu}$ et al. [2] reported that supercritical carbon dioxide $\left(\mathrm{SC}-\mathrm{CO}_{2}\right)$-treated Paulownia fortunei could remove tyloses in vessels to improve permeability. Tanaka et al. [3] reported that Douglas-fir pit aspirations, margo, and torus were destroyed after ultrasonic treatment, improving permeability. Taghiyari [6] reported

\footnotetext{
*Correspondence: kcwon@jbnu.ac.kr

Department of Housing Environmental Design, and Research Institute

of Human Ecology, College of Human Ecology, Jeonbuk National

University, Jeonju 54896, South Korea
}

that nanosilver-impregnated Polulus nigra and Carpinus betulus showed increased permeability. This is because the nanosilver particles not only removed extractives, but also destroyed the tissues of vessel elements by impregnation pressure.

As introduced above, various special methods for improving permeability have been studied, but the most widely used wood modification is heat treatment. Heat treatment disrupts wood cell walls and expands the intercellular space [7]. From this change, heat-treated wood has increased pore size and porosity and improved gas permeability $[8,9]$. In particular, Taghiyari and Avramidis [10] reported that applying the silver nano-impregnation process to heat treatment promotes microcracks in the wood cell wall, which has a positive effect on permeability. Kolay and Kang [11] observed cell wall structural changes in steam-exploded Cocos nucifera, a type of heattreated wood modification. These changes caused an 
improvement of sound absorption performance. Wood modification that can affect permeability in solid wood species can also affect sound absorption, as these two properties are related closely to the porous structure of wood [12].

This study focused on wood modification by microwaves. Microwave treatment is a type of heat treatment using microwaves [13]. Microwave heating occurs due to the polarizing effect of electromagnetic radiation at $300 \mathrm{MHz}$ and $300 \mathrm{GHz}$ [14]. In 1945, the Raytheon Company in the United States, developed and popularized a commercial microwave for cooking [13]. Since then, microwave treatment has been used in various industries [15].

Various studies on microwave treatment have been reported in the field of wood modification. The main purpose of applying microwave treatment in wood modification is to improve the permeability $[1,16,17]$.

Wang et al. [16] reported that the micro-void number increased after microwave treatment in Pinus sylvestris var. mongolica wood. Microwaving damaged the pit membranes, ray cells, and intercellular layer of tracheids. These modifications led to improved permeability and improved sound absorption performance of the wood.

Weng et al. [17] reported that, after pretreatment of Chinese fir lumber using a microwave, pit membranes were damaged, ray parenchyma cells and tracheids were detached, and micro-cracks in the radial section were observed. This treatment contributed to shortening of the drying time due to formation of new pathways for moisture transfer.

Poonia et al. [18] reported that cracks increased after microwave treatment of Eucalyptus tereticornis wood. For this reason, permeability improved and contributed to the increase of preservative absorption.

Previous studies have shown that microwave treatment of wood degrades the microstructure and increases permeability. The high permeability of wood is due to the many open pore structures $[9,19,20]$. The sound absorption coefficient of wood is related to its permeability [11, $21,22]$.

On the laboratory scale, the impedance tube mainly is used for measuring the sound absorption coefficient and allows calculation of the result in a very fast time of less $10 \mathrm{~s}$ [23]. This permits simple estimation of the permeability and impregnation properties of wood by measuring the sound absorption performance.

The effect of microwave treatment described in previous studies is limited to a few species, and there is no known information about the efficacy of microwave treatment in improving permeability and sound absorption in various species. For this study, North American Spruce (Picea sitchensis), North American Douglas fir (Pseudotsuga menziesii), and Japanese larch (Larix kaempferi) samples were prepared as very popular species for structural timber in Korea. The sound absorption coefficients of transverse, radial, and tangential sections of the three types of microwave-treated softwoods were investigated. This study showed the importance of improvement of sound absorption capability depending on tree species and anatomical plane after microwave treatment. The results will be useful for predicting the permeability and impregnation of microwave-treated wood.

\section{Materials and methods}

\section{Sample preparation}

Jeonil Timber Co., Ltd (Gimje, Jeollabuk-do, Korea) supplied 25-year-old North American Spruce (Picea sitchensis), North American Douglas fir (Pseudotsuga menziesii), and Japanese larch (Larix kaempferi) air-dried timber. Timbers were cut into cubic samples with dimensions of $4 \times 4 \times 4 \mathrm{~cm}$ (Fig. 1). Three samples were selected of each species without checking or knots. Figure 1 shows photographs of cubic samples prepared for this study.

\section{Microwave treatment and measurement of sound absorption coefficient}

The samples were immersed in water and placed in a vacuum chamber at $-0.1 \mathrm{MPa}$ for about 2 weeks. After that, they were placed in a beaker containing $300 \mathrm{~cm}^{3}$ of water and were treated in a microwave oven at $1000 \mathrm{~W}$, $2.4 \mathrm{GHz}$ for $20 \mathrm{~min}$. Finally, samples were exposed to standard room conditions for 1 month. The moisture content of samples was $12 \%$.

Sound absorption coefficients of the samples were measured by impedance tube (model: Type 4206, Bruel and Kjaer, Denmark) according to ISO 10534-2 [24]. The measurement frequency range was $100-5000 \mathrm{~Hz}$. Since a small impedance tube cannot accommodate $4 \times 4 \times 4 \mathrm{~cm}$ cubic samples, they were attached to the impedance tube without a sample holder as shown in Fig. 2. The cubic samples were insulated from outside noise using rubber clay. The sound absorption coefficients were measured in the transverse, radial, and tangential sections.

\section{Results and discussion}

\section{Sound absorption coefficients of microwave-treated samples}

Figure 3 shows sound absorption curves for the untreated and microwave-treated softwood species by anatomical direction. In all three species, the sound absorption coefficient of the transverse section was higher than those of the radial and tangential sections.

A reason for higher coefficients in the transverse direction is related to tracheid development in the longitudinal 




Fig. 1 Photographs of cubic samples before and after microwave treatment

direction. When sound waves penetrate into the tracheids, the energy hitting the cell walls is converted into thermal energy and lost [25]. On the other hand, in the radial and tangential sections, the sound absorption coefficient was significantly lower because of lack of a pore structure through which the sound waves can penetrate.

After microwave treatment for $20 \mathrm{~min}$, the sound absorption coefficients of the three sections of the three species of softwood showed increasing trends at frequencies above $2000 \mathrm{~Hz}$. Table 1 provides the average sound absorption coefficient at $2000-5000 \mathrm{~Hz}$ before and after microwave treatment depending on anatomical direction. To statistically determine the significance of the difference between the average values of the two groups, paired $t$ test was performed. In all three species and three planes, the sound absorption coefficient increase after microwave treatment was significant. The spruce average sound absorption coefficients at 2000$5000 \mathrm{~Hz}$ were higher by $6.9 \%$ for the transverse section, $20.0 \%$ for the radial section, and $31.7 \%$ for the tangential section. The Douglas fir coefficients were higher by $28.9 \%$ for the transverse section, $19.1 \%$ for the radial section, and $50.0 \%$ for the tangential section. The larch coefficients were higher by $16.7 \%$ for the transverse section, $37.2 \%$ for the radial section, and $38.8 \%$ for the tangential section. This occurs, because the vapor generated rapidly inside the wood by microwave treatment quickly escapes to the outside and exfoliates the tracheids and parenchyma cells. In addition, microwave treatment of wood allows the soft resin inside the pores to escape [16].

In this study, Douglas fir and larch responded to microwave treatment better than spruce in a transverse section. In this study, the resin content of the Douglas fir and larch specimens was higher than that of spruce.

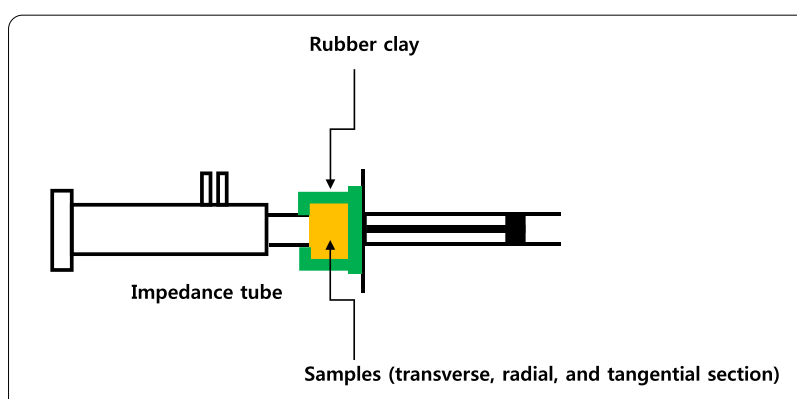

Fig. 2 Schematic of the impedance tube for measurement of sample sound absorption coefficients

These resins most likely escaped into the transverse section.

The sound absorption coefficient of porous materials is related to gas permeability [26]. In particular, in wood, a higher sound absorption coefficient indicates higher permeability $[11,21,22]$. A higher permeability reflects higher open-pore porosity, which can cause rapid dissipation of sound energy [11, 21, 22].

In this study, the sound absorption performance was improved in all three sections of softwoods after microwave treatment, indicating that the open-pore porosity also increased. Wu et al. [27] suggested that open-pore porosity of wood calculated by skeletal density is a key parameter for prediction of wood impregnation. Thus, increase in sound absorption performance of wood can be predicted based on wood impregnation ability. In the future, it is necessary to study the relationship of the predictive equation of wood impregnation according to the increase in sound absorption performance.

Therefore, the sound absorption coefficient measurement results of the three sections can predict the 



(b) Douglas-fir
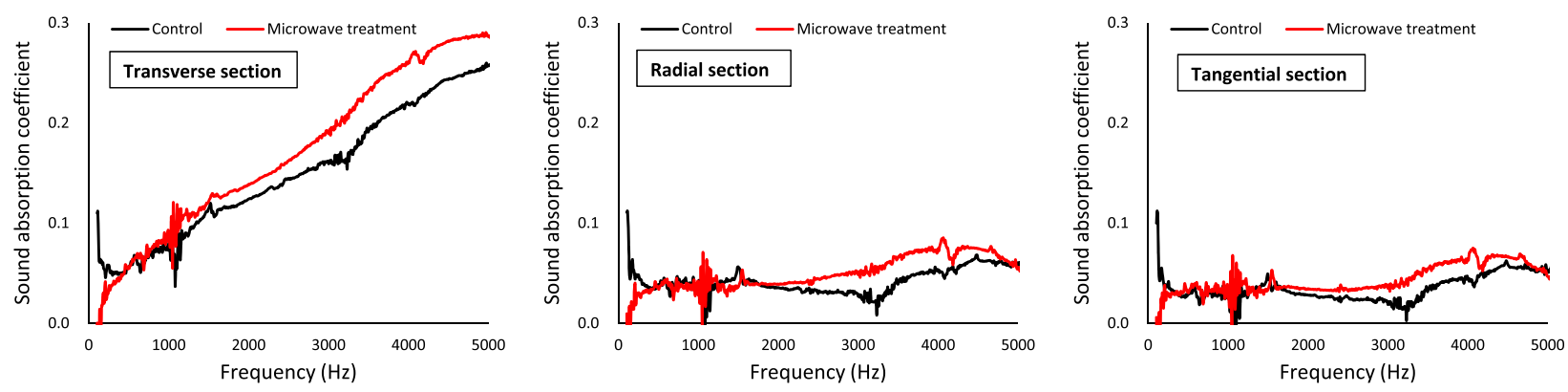

Fig. 3 Sound absorption curves of three softwood species before and after microwave treatment depending on anatomical direction

Table 1 Average sound absorption coefficient of three softwood species at 2000-5000 Hz before and after microwave treatment depending on anatomical direction

\begin{tabular}{|c|c|c|c|c|c|c|c|c|c|}
\hline & \multicolumn{3}{|l|}{ Spruce } & \multicolumn{3}{|l|}{ Douglas-fir } & \multicolumn{3}{|l|}{ Larch } \\
\hline & Transverse & Radial & Tangential & Transverse & Radial & Tangential & Transverse & Radial & Tangential \\
\hline \multirow[t]{2}{*}{ Control } & 0.159 & 0.038 & 0.041 & 0.151 & 0.042 & 0.036 & 0.191 & 0.043 & 0.036 \\
\hline & -0.039 & -0.014 & -0.014 & -0.036 & -0.013 & -0.014 & -0.043 & -0.013 & -0.014 \\
\hline \multirow{2}{*}{$\begin{array}{l}\text { Microwave } \\
\text { treatment }\end{array}$} & 0.17 & 0.046 & 0.054 & 0.187 & 0.05 & 0.054 & 0.223 & 0.059 & 0.05 \\
\hline & -0.043 & -0.014 & -0.013 & -0.043 & -0.014 & -0.013 & 0.05 & -0.013 & -0.013 \\
\hline$t^{\mathrm{a}}$ & $-33.6^{* *}$ & $-21.2^{* *}$ & $-29.4^{* *}$ & $-70.8^{* *}$ & $-21.3^{* *}$ & $-42.0^{* *}$ & $-63.9^{* *}$ & $-35.1^{* *}$ & $-33.2^{* *}$ \\
\hline
\end{tabular}

Numbers in parentheses are standard deviations

${ }^{\mathrm{a}} t$ value

${ }^{* *} p<0.001$ 
improvement of open pores after microwave treatment. These data will be helpful in predicting the permeability and impregnation of wood after microwave treatment.

\section{Conclusions}

The sound absorption performance after microwave treatment of three softwood species was investigated. The conclusions are as follows.

1. Microwave treatment increased the sound absorption coefficient of the transverse, radial, and tangential sections of softwoods.

2. The increases in average sound absorption coefficients after microwave treatment of spruce at 2000$5000 \mathrm{~Hz}$ were $6.9 \%$ higher for the transverse section, $20.0 \%$ higher for the radial section, and $31.7 \%$ higher for the tangential section. Douglas fir coefficients were $28.9 \%$ higher for the transverse section, $19.1 \%$ higher for the radial section, and 50.0\% higher for the tangential section. Larch coefficients were $16.7 \%$ higher for the transverse section, 37.2\% higher for the radial section, and $38.8 \%$ higher for the tangential section.

3. As both permeability and sound absorption coefficients are dependent on the porous structure of wood, alterations in sound absorption coefficient can be measured for use in impregnation and preservation processes.

\section{Acknowledgements}

This research was supported by the Basic Science Research Program through the National Research Foundation of Korea (NRF) funded by the Ministry of Education (NRF-2019R111A3A02059471) and was supported under the framework of an international cooperation program managed by the NRF of Korea (NRF-2020K2A9A2A08000181). Authors are also thankful to the "The Business Startup Incubator Support Program" supported by the Ministry of Education and National Research Foundation of Korea.

\section{Authors' contributions}

ESJ: first author, conceptualization, methodology, experiment, data analysis, writing — original draft, and writing — review and editing. CWK: corresponding author, supervision and writing - review and editing. Both authors read and approved the final manuscript.

\section{Funding}

NRF-2019R111A3A02059471 and NRF-2020K2A9A2A08000181.

\section{Availability of data and materials}

Not applicable.

\section{Declarations}

\section{Competing interest}

The authors have no competing interests.

Received: 3 August 2021 Accepted: 24 December 2021

Published online: 04 January 2022

\section{References}

1. Torgovnikov G, Vinden P (2009) High-intensity microwave wood modifcation for increasing permeability. For Prod J 59(4):84

2. Xu H, Taghiyari HR, Clauson M, Milota MR, Morrell JJ (2019) Effect of supercritical carbon dioxide treatment on gas permeability of Paulownia fortunei heartwood and sapwood. Wood Fiber Sci 51(1):1-5

3. Tanaka T, Avramidis S, Shida S (2010) A preliminary study on ultrasonic treatment effect on transverse wood permeability. Maderas Cienc Tecnol 12(1):03-09

4. Taghiyari HR, Malek BM (2014) Effect of heat treatment on longitudinal gas and liquid permeability of circular and square-shaped native hardwood specimens. Heat Mass Transf 50(8):1125-1136

5. Militz H, Lande S (2009) Challenges in wood modification technology on the way to practical applications. Wood Mat Sci Eng 4(1-2):23-29

6. Taghiyari $\mathrm{H}$ (2012) Correlation between gas and liquid permeability in some nanosilver-impregnated and untreated hardwood. J Trop For Sci 24:249-255

7. Park Y, Jeon W-s, Yoon S-m, Lee HM, Hwang W-j (2020) Evaluation of cellwall microstructure and anti-swelling effectiveness of heat-treated larch wood. J Korean Wood Sci Technol 48(6):780-790

8. Kang C-W, Li C, Jang E-S, Jang S-S, Kang H-Y (2018) Changes in sound absorption capability and air permeability of Malas (Homalium foetidum) specimens after high temperature heat treatment. J Korean Wood Sci Technol 46(2):149-154

9. Jang E-S, Kang C-W (2019) Changes in gas permeability and pore structure of wood under heat treating temperature conditions. J Wood Sci 65(1):1-9

10. Taghiyari HR, Avramidis S (2019) Specific gas permeability of normal and nanosilver-impregnated solid wood species as influenced by heat-treatment. Maderas Cienc Tecnol 21(1):89-96

11. Kolya H, Kang C-W (2021) Effective changes in cellulose cell walls, gas permeability and sound absorption capability of Cocos nucifera (palmwood) by steam explosion. Cellulose 28(9):5707-5717

12. Jang E-S, Kang C-W (2021) Sound absorption characteristics of three species (binuang, balsa and paulownia) of low density hardwood. Holzforschung. 75(12):1115-1124. https://doi.org/10.1515/hf-2021-0049

13. Osepchuk JM (1984) A history of microwave heating applications. IEEE Trans Microw Theory Tech 32(9):1200-1224

14. Tang J, Feng H, Lau M (2002) Microwave heating in food processing. Adv Bioprocess Eng 1:1-43

15. Adam D (2003) Microwave chemistry: out of the kitchen. Nature 421(6923):571-573

16. Wang D, Peng L, Zhu G, Fu F, Zhou Y, Song B (2014) Improving the sound absorption capacity of wood by microwave treatment. BioResources 9(4):7504-7518

17. Weng X, Zhou Y, Fu Z, Gao X, Zhou F, Jiang J (2021) Effects of microwave pretreatment on drying of $50 \mathrm{~mm}$-thickness Chinese fir lumber. J Wood Sci $67(1): 1-9$

18. Poonia PK, Tripathi S, Sihag K, Kumar S (2015) Effect of microwave treatment on air permeability and preservative impregnation of Eucalyptus tereticornis wood. J Indian Acad Wood Sci 12(2):89-93

19. Jang E-S, Yuk J-H, Kang C-W (2020) An experimental study on change of gas permeability depending on pore structures in three species (hinoki, Douglas fir, and hemlock) of softwood. J Wood Sci 66(1):1-12

20. Ahmed SA, Chun SK (2011) Permeability of Tectona grandis L. as affected by wood structure. Wood Sci Technol 45(3):487-500

21. Taghiyari H, Zolfaghari H, Sadeghi M, Esmailpour A, Jaffari A (2014) Correlation between specific gas permeability and sound absorption coefficient in solid wood. J Trop For Sci 1(26):92-100

22. Kang C-W, Jang E-S, Lee N-H, Jang S-S, Lee M (2021) Air permeability and sound absorption coefficient changes from ultrasonic treatment in a cross section of Malas (Homalium foetidum). J Wood Sci 67(1):1-5

23. Olynyk D, Northwood T (1964) Comparison of reverberation-room and impedance-tube absorption measurements. J Acoust Soc Am 36(11):2171-2174

24. ISO 10534-2 (2001) Acoustics-Determination of sound absorption coefficient and impedance in impedance tubes-Part 2 transfer-function method. International Organization for Standardization, Geneva

25. Watanabe T, Matsumoto T, Kinoshita N, Hayashi H (1967) Acoustical study of woods and wood products. J Jpn wood res soc 13(5):177-182 
26. Cao L, Fu Q, Si Y, Ding B, Yu J (2018) Porous materials for sound absorption. Compos Commun 10:25-35

27. Wu G, Shah DU, Janeček E-R, Burridge HC, Reynolds TP, Fleming PH, Linden P, Ramage MH, Scherman OA (2017) Predicting the pore-filling ratio in lumen-impregnated wood. Wood Sci Technol 51(6):1277-1290

\section{Publisher's Note}

Springer Nature remains neutral with regard to jurisdictional claims in published maps and institutional affiliations. 